\title{
MULHER NASCE MULHER? CLARICE LISPECTOR: COLUNISTA E AUTORA DE A HORA DA ESTRELA
}

Lídia Maria Nazaré Alves*

RESUMO :

No primeiro momento desse trabalho me detive nos artigos escritos por Helen Palmer (pseudônimo de Clarice Lispector) nos fins da década de 50 e começos da década de 60. Esses textos foram publicados no jornal 0 Correio da Manhã, com o título de "Correio feminino". Nesse pequeno espaço a colunista dava conselhos para uma provâvel construção da feminilidade da mulher burguesa dentro dos esquemas ideológicos desenhados pelo sistema de sexo-gênero. Em um segundo momento, aproximeime do estudo de A hora da estrela, onde se constata a desconstrução da imagem de mulher elaborada nos artigos.

PALAVRAS-CHAVE: gênero, construção, desconstrução, negociação.

Penso que o título desse ensaio possa sugerir um certo nonsense aos que se dedicam aos estudos de gênero e aos leitores familiarizados com a obra de Clarice Lispector. Isso porque ele abala algumas idéias quase cristalizadas no meio acadêmico. Com Simone de Beauvoir acredito que "ninguém nasce mulher, torna-se mulher". Essa idéia vêmo-la reiterada em obras que nos levam a perceber que os sistemas culturais criam o gênero masculino e feminino. Idéia polêmica porque a cultura tradicional tende para o ocultamento dessa construção, fazendo-nos acreditar na originalidade dos gêneros, já que isso thes convém, porque "refuerzam lineamientos de poder, dominancia y autoridad", conforme Nelly Richard (1993: 11). Uma das escritoras que atentam para o desocultamento da originalidade do gênero é Clarice Lispector. Ela o faz tanto pelo viés temático quanto pelo viés expressivo-simbólico. No primeiro caso, suas personagens são levadas à busca de seu eu "sem máscaras". No segundo caso, ela tece sua narrativa calcada na desconfiança de que a linguagem, enquanto

* Mestre em Letras: Estudos Literários (Área de concentração: Teoria da Literatura), 2001. 


\section{EM TESE}

Belo Horizonte, v. 6, p. I-253, ago. 2003

sinal estável, não é capaz de representar o ser em sua totalidade (existe algo, próprio do ser, que é da ordem do inominável: trata-se de sua identidade pura, de sua plenitude). Uma forma de abordar essa impossibilidade é deslizando do literário (onde a comunicação se estabelece entre texto e leitor) para o literal (onde 0 significado se dilui, virando sopro).

0 que observamos até aqui é que as idéias de Simone de Beauvoir e Clarice Lispector, complementam-se. Sendo assim poderíamos perguntar qual a razão do qüestionamento no título do ensaio. 0 tom interrogativo advém do estranhamento que tive ao me deparar com a leitura da novela, também de Clarice Lispector, A hora da estrela. Nesse espaço, a construção da personagem Macabéa não segue os mesmos paradigmas das construções das personagens femininas de importantes romances e contos anteriores. A título de exemplificação, recorro a GH de A Paixão Segundo GH. Naquele romance a protagonista começa e termina a ação num processo contínuo de descoberta de si mesma e do Outro: "Mas agora, através de meu mais difícil espanto - estou enfim caminhando em direção à destruição do que construí, caminho para a despersonalização" (Lispector, 1997: 177). O mesmo ocorre com a personagem Ana do conto "Amor" de Laços de Família. Neste, ela é levada a realizar a travessia do mundo exterior para o mundo interior, locus onde re-encontra seu antigo "eu" quase já esquecido, como sugere o seguinte excerto: "Todo o seu desejo vagamente artístico encaminhara-se há muito no sentido de tornar os dias realizados e belos. Com o tempo, seu gosto pelo decorativo se desenvolverá e suplantará a íntima desordem" (Lispector, 1960: 18).

Contrariamente a essas personagens, a construção de Macabéa se dá por outras vias. Pode-se dizer que ela é o avesso das outras. Alienada, é levada a fazer a travessia da sua vida "primária", interior, para a vida exterior. Despreparada para a empresa, é atropelada e morre. Só esse trabalho diferenciado na construção das personagens já seria motivo bastante para muitos questionamentos e reflexões. Todavia, o que reforça nosso interesse são as palavras escritas nas páginas finais da novela. Ei-las: "Seu esforço de viver parecia uma coisa que, se nunca experimentara, virgem que era, ao menos intuíra, pois só agora entendia que mulher nasce mulher desde o primeiro vagido" (Lispector, 1992: 103). Detendo-me nesse ponto, perguntome sobre as possíveis causas que levariam a autora à tessitura de uma história ao avesso das anteriores. Desse qüestionamento nasceu o título desse ensaio. 
Podemos destacar alguns motivos. Primeiro, o desejo de que sua obra atingisse um público maior, a fim de que sua personagem fosse conhecida. Diz o narrador interposto e nomeado Rodrigo S.M.: "0 que escrevo é mais do que invenção, é minha obrigação contar sobre essa moça entre milhares delas. É dever meu, nem que seja de pouca arte, o de revelar-1he a vida" (Lispector, 1992: 27). Para isso precisava atraí-1os. Daí a clareza da história de Macabéa. Segundo, o desejo manifesto de safar-se de uma hipotética acusação, conforme o narrador: "É. Parece que estou mudando de modo de escrever. Mas acontece que só escrevo o que eu quero, não sou um profissional - e preciso falar dessa nordestina senão sufoco. Ela me acusa e o meio de me defender é escrever sobre ela" (31). Terceiro, o desejo de desabafo. Novamente o narrador: "Porque há o direito ao grito. Então eu grito" (27).

Reunindo todos esses motivos, podemos dizer que $A$ hora da estrela revela a grande necessidade da escritora de colocar o leitor a par (só que de forma mais explícita) da existência daquele sistema cultural abandonado por GH e Ana. Na novela são veiculados vários aparelhos ideológicos de estado (Althusser, 1980: 43-4). 0 olhar da escritora explora mais os da informação (rádio, imprensa e cinema), que acreditamos funcionar como uma "tecnologia de gênero", na esteira de Teresa de Lauretis $^{1}$ (1994: 206).

A personagem nordestina é construída em oposição aos estereótipos veiculados pelos mass media. Seu hobby é colecionar anúncios de jornais velhos e ir uma vez por mês ao cinema ver Marylin Monroe. Aliás, ela deseja ser igual à artista hollywoodiana. Posteriormente, deseja ser bonita para atrair o olhar masculino. Todavia, não consegue nem uma coisa nem outra. Morre. Curioso é que o narrador sente-se aliviado com o final. "E agora - agora só me resta acender um cigarro e ir para casa. Meu Deus, só agora me lembrei que a gente morre. Mas - mas eu também?! Não esquecer que por enquanto é tempo de morangos. Sim" (Lispector, 1992: 106). Mas não é assim que nos sentimos no final dessa história "inacabada" segundo Clarice Lispector (1992: 22). Certas expressões utilizadas, sobretudo nas páginas finais, causam certo mal estar no leitor. Eis algumas delas: "Até tu Brutus?!", "Não me consumam! Não sou vendável!", "Ai de mim, todo na perdição e é como se a grande culpa fosse minha. Quero que me lavem as mãos e os pés e depois - depois que os untem com óleos santos de tanto perfume" (Lispector, 1992: 105-5). Esse mal estar nos leva a 


\section{EM TESE}

Belo Horizonte, v. 6, p. I-253, ago. 2003

buscar em outras obras da autora algo que justifique mais a escritura dessa obra derradeira.

Nessa nossa busca descobrimos uma outra faceta de Clarice Lispector velada sob o pseudônimo de Helen Palmer. A colunista era responsável pelos artigos da coluna "Correio feminino", do Jornal O Correio da Manhã, ao final da década de 50 e início da década de 60. A coluna era editada às quartas e sextas-feiras, no segundo caderno do jornal, de agosto de 1959 a fevereiro de 1961. Contrariando sua produção literária ("hermética" para alguns e promovendo "a inscrição do sujeito feminino na história" para outros) mas bastante parecidos (tanto pelo viés temático quanto pelo viés expressivo-simbólico), com a novela $A$ hora da estrela, os artigos podem ser analisados como um dos tentáculos do sistema de genderização cultural. Seu discurso promovia o estabelecimento de uma fronteira muito rígida entre o masculino e o feminino. 0 título da coluna fala por si e o tom de alguns artigos faz-nos ver que essa fronteira já apresentava suas fissuras, dada a emancipação da mulher, possível razão para que a voz da colunista se fizesse ouvir, contribuindo assim com a manutenção da ordem simbólica. 0 artigo intitulado "Qualidades para tornar a mulher mais sedutora", acena para o fato:

Os tempos modernos trouxeram a emancipação da mulher em quase todos os campos. Eis um grande bem. No entanto, muita confusão se fez em tôrno [sic] disto e o que se vê é que muitas representantes do sexo feminino entendem que ser emancipada e ter personalidade marcante é imitar os homens em tôdas [sic] as suas qualidades e defeitos. A agressividade, o hábito de tomar atitudes pouco distintas em público e muitas outras coisas vêm prejudicando a beleza da mulher e tirando-1he o predicado que mais agrada os homens: sua feminilidade. A faculdade de ser diferente dos homens em atitudes, palavras, mentalidade. (Palmer, 1960)

Segundo a colunista a feminilidade é a faculdade de ser diferente dos homens em atitudes, palavras, mentalidade. Dito isso, ao relembrar à mulher emancipada o que é o próprio do feminino, resgata os mesmos mitos construídos pela tradição: saúde, mocidade, beleza e, conseqüentemente a maternidade e os cuidados com o lar. Todos voltados para a mulher como objeto simbólico ou, como prefere Pierre Bourdieu (1999: 82), como "ser percebido". Cedamos-1he a palavra:

A dominação masculina, que constitui as mulheres como objetos simbólicos, cujo ser (esse) é um ser-percebido (percipi), tem por efeito colocá-las em 
permanente estado de insegurança corporal, ou melhor, de dependência simbólica: elas existem primeiro pelo, e para, o olhar dos outros, ou seja, enquanto objetos receptivos, atraentes, disponiveis. Delas se espera que sejam 'femininas', isto é, sorridentes, simpáticas, atenciosas, submissas, discretas, contidas ou até apagadas. E a pretensa 'feminilidade' muitas vezes não é mais que uma forma de aquiescência em relação às expectativas masculinas, reais ou supostas, principalmente em termos de engrandecimento do ego.

0 artigo do dia 23 de dezembro de 1959, intitulado "0 dever da faceirice", esclarece.

A faceirice é, portanto, obrigação para a mulher. Nem a mulher de negócios, nem a cientista, nem a mulher de letras, nem a esportista dispensam êsse [sic] dever primordial para a conquista do homem. Afinal, podemos pensar deles o que quisermos, mas precisamos deles para completar a nossa felicidade, não é mesmo? Façamos, portanto, por conquistá-1os. (Palmer, 1959)

Tudo indica que, além do trabalho da colunista ter que fazer valer o referido sistema mítico, também ela deveria estar de acordo com ele ou, então, fingir que estava. Ou ainda, pelo menos ter experimentado os traços distintivos da classe dominante. De fato, lembra-nos Bourdieu, há uma inclinação social de se oferecer às mulheres funções sociais análogas às que thes foram confiadas pela tradição, como a produção de bens e serviços simbólicos. E essas funções surtem melhores resultados quando destinadas às mulheres da pequena burguesia, porque, diz ele,

(m)arcadas pela aspiração de se identificarem com os modelos dominantes como o comprova sua tendência à hipercorreção estética e lingüística -, elas estão particularmente inclinadas a se apropriarem, a qualquer preço (isto é, na maior parte das vezes, a crédito), das propriedades distintivas, por serem as que distinguem os dominantes, e a contribuírem para sua imperativa divulgação em favor, sobretudo, do poder simbólico circunstancial, que pode assegurar a seu proselitismo de recém-convertidas uma posição no aparelho de produção e de circulação dos bens culturais (por exemplo, em jornal feminino). (Bourdieu, 1999: 121)

Embora a citação possa parecer direcionada - acredito que muitos pensam assim - era esse o papel de Helen Palmer: o de contribuir para a produção desses sinais de distinção que iam dos produtos ou serviços de estética à alta costura ou à cultura erudita que ela, às vezes, fazia circular. Atitude bastante coerente com o tipo de vida que Lispector tinha antes de voltar para o Brasil. A leitura da carta enviada à sua sogra elucida nossa fala: 


\section{EM TESE}

Belo Horizonte, v. 6, p. I-253, ago. 2003

Pretendemos aproveitar o fato de termos alguém de tão absoluta confiança (diplomada) para umas férias, talvez na Côte d'Azur. Maury e eu estamos precisando. - Nenhuma novidade mais, senão que esta semana é cheia de graves compromissos sociais ... 0 ministro e a familia almoçaram hoje aqui (seu trabalho de tricô foi muito admirado), hoje ainda temos um cocktail. Amanhã jantamos com o presidente da Confederação na casa do ministro; almoçaremos com 0 ministro do Exterior na Legação. Em seguida devemos retribuir as amabilidades do ministro-conselheiro da França com um jantar ... (Gotlib, 1995: 261)

Obviamente nosso argumento não impede que se refleta de forma mais acurada sobre a veracidade da liberdade (ou não) de ação da colunista. Abordando essa questão, Bourdieu afirma que essas "trabalhadoras livres" acabam sendo vítimas do sistema do qual pensavam estar libertas.

Depois dessa exposição cremos que já podemos compreender os motivos que desencadearam a trama da última novela. A autora deu a sua parcela de contribuição na construção de um sistema que promove a diferença de gênero e das relações sociais de gênero, porque desconsidera a diferença. Por isso todo o mundo de Helen Palmer foi transladado para $A$ hora da estrela. É nessa última novela que a escritora, já bastante fragilizada pelas agruras da vida e também por conta do câncer que a tomava dia-a-dia, teve a oportunidade de desconstruir as idéias divulgadas naquele período da juventude, quando escrevia para a coluna. Essa desconstrução, como acontece também noutras obras de Clarice, se dá de forma bastante tranqüila, equilibrada. Trata-se mais de

una táctica para descentrar, una manera de abordar la lectura que ante todo nos permite advertir la centralidad del componente central. Luego, intenta subvertirlo para que la parte marginada pase a ser la central y temporariamente elimine la jerarquía. (Powell e Howel1, 1977: 28).

De fato as estrelas hollywoodianas, que ocupavam o centro na coluna, ocupam a margem na novela. Eis uma forma inteligente de chamar a atenção para 0 Outro, no caso uma nordestina, que não se enquadrava nos padrões de feminilidade de Helen Palmer. Para acentuar melhor esta questão a escritora opta pelo grotesco no trabalho de construção da personagem Macabéa. Contrariando a idéia da colunista, que via no corpo o depositário das especificidades de gênero, o corpo de Macabéa é doente e incapaz de absorvê-las. Um corpo signo de denúncia e resistência. Denúncia porque se reconhece excluído do socius devido à impossibilidade de ser genderizado 
nos moldes dos discursos dominantes. Resistência, porque reconhece que sua construção prescinde de sua ação e vontade primeiras. Espécie de corpo-objeto no qual o discurso dominante opera as marcas de gênero. Macabéa é pois a metáfora de que se serve a autora para denunciar quaisquer práticas pedagógicas hegemônicas destinadas à formação e/ou reprodução do gênero, cerceando à mulher (mas também ao homem) seus direitos como pessoa humana.

Já querendo concluir esse estudo acredito ter elucidado a frase final da novela que nos ocupou e motivou. Macabéa é mulher. Só que esse seu "ser feminino" aparece abstraído das especificidades de gênero - "vida primária que respira, respira, respira" - que a tecnologia de gênero apregoa. A criação dessa personagem nesse estágio primário de vida acena para a necessidade de (re)organização dos nossos arranjos de gênero e faz vermos melhor que sexo e gênero não são a mesma coisa. Enquanto o primeiro está ligado ao biológico, o segundo está mais ligado ao social.

Como vimos, a coluna de Helen Palmer é um ponto interessante para a crítica feminista que deseja colocar a descoberto os processos textuais de construção de gênero, desnaturalizando-os. Mas esses estudos devem ocupar-se igualmente de outras formas de exclusão, optando pelo estudo de todas as práticas sociais que se ocupam da formação de sujeitos excluídos devido à impossibilidade de inclusão nesse processo seletivo e hierárquico de genderização.

NOTA:

1. Como bem lembrou Teresa de Lauretis, o sistema de sexo-gênero além de ditar a identidade de gênero, "atribui significados outros aos indivíduos na sociedade, tais como: valor, prestígio, posição de parentesco, status dentro da hierarquia social etc." (1994: 212). 


\section{EM TESE}

Belo Horizonte, v. 6, p. I-253, ago. 2003

RESUMEN :

Este trabajo surgió del deseo de reflexionar sobre dos posturas antagónicas que notamos en la escrita de Clarice Lispector. Las crónicas escritas a finales de la década de 50 y comienzos de la de 60 y A hora da estrela, de la década de 70. En un primer momento la columnista daba consejos para una probable "construcción" de la feminidad de la mujer burguesa. En un segundo momento observamos la desconstrucción de la imagen de mujer elaborada en las crónicas.

PALABRAS CLAVE: género, construcción, desconstrucción, negociación.

\section{REFERÊNCIAS BIBLIOGRÁFICAS}

ALTHUSSER, Louis. Ideologia e aparelhos ideológicos do Estado. 3. ed. Lisboa: Presença; São Paulo: Martins Fontes, [s. d.].

BEAUVOIR, Simone de. 0 segundo sexo. v. 1 e v. 2. 9. ed. Trad. Sérgio Milliet. Rio de Janeiro: Nova Fronteira, 1980.

BOURDIEU, Pierre. A dominação masculina. Trad. Maria Helena Kühner. Rio de Janeiro: Bertrand Brasil, 1999.

GOTLIB, Nádia Battela. Clarice: uma vida que se conta. 5. ed. São Paulo: Ática, 1995.

LAURETIS, Teresa de. A tecnologia de gênero. In: Hollanda, Heloisa Buarque de. (Org.). Tendências $e$ impasses: o feminismo como crítica da cultura. Rio de Janeiro: Rocco, 1994. p. 206-242.

LISPECTOR, Clarice. A hora da estrela. 19. ed. Rio de Janeiro: Francisco Alves, 1992.

$\overline{1997}$ - A paixão segundo G.H. Rio de Janeiro: Rocco, Sabiá, 1960.

Laços de família: contos. 4. ed. Rio de Janeiro:

PALMER, Helen [Clarice Lispector] Correio feminino: feira de utilidades. In: O Correio da Manhã. Rio de Janeiro, 1959-60.

RICHARD, Nelly. Masculino/ Feminino: práticas de la diferencia y cultura democrática. Santiago: Francisco Zegers Editor, 1993. 


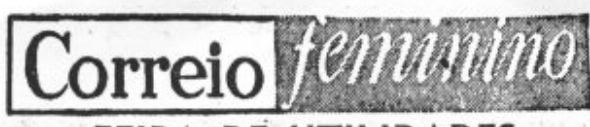

FEIRA DE UTILIDADES HELEN PALMER

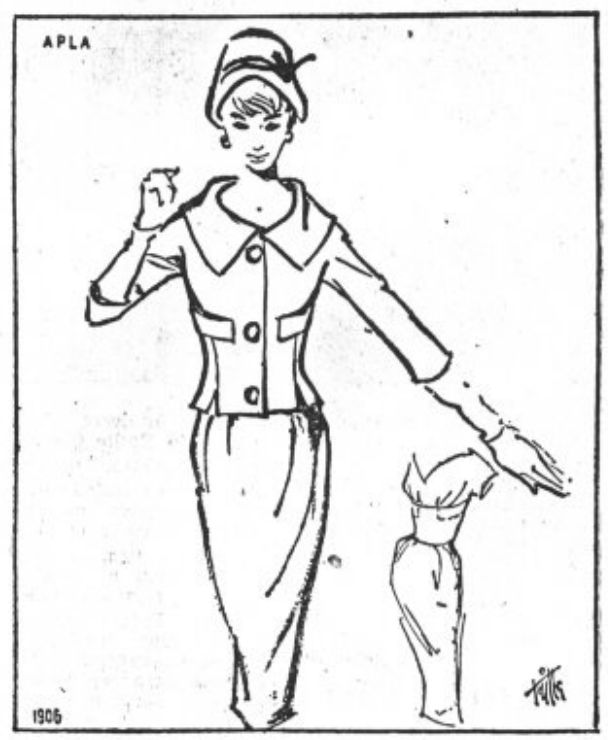

Vestido e jaquetada semi-entalhada, com dois bolsinhos baixos e grande gola aberta. Mangas trêsquartos. O vestido leva amplo corpete

SE O SEU FILHO E "PROBLEMA"

A eulpa, minha amiga, $t$ do método de edueaça que vocé esta ompregando. E' preciso compreender o seu filho. E o caminho

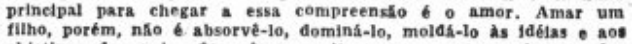
objetivos dos pals. Esse erro, multo comum entro pais que desejam ver seus fillos vitoriosos, provoca na eriança ou na sdolescente a reaçio para fugir a sufocante atmostera do lar. A personalidade désses jovens quer firmar-se, é O far, mesmos. Procuram ngir "contra" os ansinamentos as imposiços dos pais, dando a impressso a estes de Ingratidiso, maus instintos of falta de sentlmentos. Cria-se o amblente de descontiança o ressentimento mútuos.

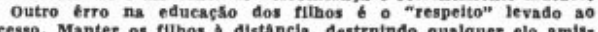
excesso. Manter os filhos a distancia, destraindo qualquer elo amissentimento de abandono e solidaso. "Quando ele estiver malor para compreender-me..." 6 como alguns pals desculpam essa maneira de proceder. Errado. Quando a criança tiver se transformado em adulto sera tarde demais. Nada mais podera entáo unl-lo aos pals. Tambem a bondade excessiva, a condescendencla exagerada, afetam e prefudicam o seu fitho. Os pais que acedem a todos os caprich de bringuedos mals fraco, o fitho n⿳亠丷厂巾 sente nos pals a protecso, a compreensio o a poio de que precisa. Sente-se, pelo contrário, desamparado. Perde a confiancs que deveria ter nos adultos,

Náo se formulam leis gerais para a eđucaşáo de uma erlança. E' verdade que existe a lel-base para tódas, o que é a compreensaso atraves do amor. Mas os métodos de aplieá-la variam de aedrdo com o temperamento, a sensibilldade, os sentimentos de cada um descobri-lo para conquistá-lo e fazế-lo frutiflear.

$$
\text { * * * * }
$$

\section{MANCHAS DE LAPIS:TINTA}

Para retirá-las, aplique uma mistura de ficool e amonfaco na proporçío de 2 para 1, esfregando o local manchado. Pode repetir

\section{PARA REAVIVAR A COR DOS TECIDOS}

Quando a côr dos tecidos estiver desbotada, náo pela açấa quer razšo, pode-se reavivá-la com massa de batatas ou fécula de batatas.

$$
\text { *** }
$$

LEIS PARA OS FUMANTES

- Quando estiver em algum local onde seja proibido fumar. obedeça a essa proiblç̧io que tem sua raztio de ser.

um doente, no de no quarto de ou $\mathrm{em}$ locais pouco arejados como um elevador,

voce vai entre na casa, onde voce vai de visita, com o cl-
garro aceso, $\mathbf{E}^{\prime}$ falta de educkgarro

$$
\text { * * * * }
$$

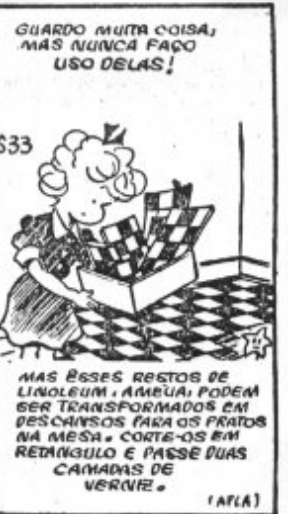

NAO SOMENTE O ROSTO DEVE SER EMBELEZADO

So voed culdar de seu rosto, massaged-lo, pintá-lo, - esquecer os outros velhos, enrugados elm pouco um estará môcos o bonito. cremes e o "maquillage" até onde alcançar o seu decote. Tambem os braços e as pernas deverîno receber seus cuidados de beleza.

$$
\text { * * * }
$$

"A bondade consiste em estimar as pessoas mals do que elas

$$
\text { * * * * JoUBERT }
$$

\section{AS APARENCIAS ENGANAM}

Madame de Montespan ficou famosa pela rlqueza ostensiva do deus vestidos. Usava-os de ouro, assombrando e provocando a inveja brir que, sob aquelas vertes. Estas, porem, naso tardaram a descotheres mais mal cheirosas e sujas que ja houvera uma das mupassaram ao desprezo a is anedotas.

\section{MEDICINA \\ DE EMERGENCIA

$$
\text { * * * }
$$

Em caso de fntoxicaçấo, de- A causa désso inimigo da beleI ou leite ou 15 a $30 \mathrm{~g}$ de copos de nervosa, perda de horas do sotrigo batidas num litro de água, tal, Como tratamento ou menpara neutrallizar o efeito do - pols todo mal deve auxiliar toxico. Pode-se tomar também batido na sua origem ser com4 elaras de ovo batidas num 11- uma massagem no locai, com tro de agas. Deve-se provocar um bom creme, com as pontas ventito e, se tor conheeldo o dos dedos, delicadamente, em
veneno Ingerido, deve-se minis- movimentos circulares, ou em trar imedlatamente o antidoto. movimentos circulares, ou em

$$
\text { * * * }
$$

\section{LIMAO PARA DORES DE ESTOMAGO}

Umas gotas de limão adicionadas so eafe 6 um ótimo calmante para dores e cólicas de estomago.

\section{CONSELHOS OTEIS}

D. N1. Para impermeabilizaçắo das solas dos sapatos de couro basta velo 2 opsarar sobre eles um pouco de bleo de rícino.

algumas gotas de limšo de seda branca amarelecam. pingue

3. Para abrir um caixote com facilidade, basta passar-lhe na bordas um pouco de sabfo ou de espermacete.

\section{CURIOSIDADE}

Conta a lenda que a soda fol descoberta pela esposa de um Imperador chines, a qual passeava pelos fardins de paláclo quando so interessou por uns bichinhos que estavam devorando as folhns volta de si mesmos, amoreira - e que teclam um longo flo aproximou-se e puxou a ponta de um daqueles fios, imperatria bentá-lo. Encantada com a sua maciez, o seu brilho e sem arrentencia, levou-o para o imperador, que também se interessou, Es. tava descobeta a seda, que cobriria e enfeitaria as mulheres msis bonitas do mundo. A China guardou o segredo da extraç̧̌o da sêda, enriquecendo com a exportaçaso desse tecido para a Pérsila, Roma e mancar do arrancar de

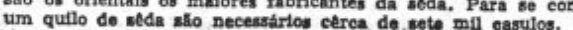

